Richard Buono, Associate at Blacks Solicitors, lists ten essential points that need to be carefully considered when selling the assets of a dental practice. hen selling a dental practice, there is more to think about other than simply if it is the right time or right price. Careful planning and preparation are essential, but there may also be other elements that you haven't yet considered. It can be overwhelming but it needn't be stressful. Here are some steps to bear in mind to ensure the sale goes as smoothly as possible.

\section{Do your research}

With any luck, several buyers will already be interested in your practice. Carry out research into each buyer and make sure that you choose the appropriate offer - the highest may not be the best! Also, remember to have a back-up plan and keep details of unsuccessful bidders on file in case there are any issues or complications with the sale. In addition, you will need to make sure that the solicitor who will be handling the sale is sufficiently experienced in dealing with sales of dental practices, because there are many matters particular to dental practices which will need to be covered properly in the sale documentation.

$2^{\mathrm{s}}$ Show me the money

Does your buyer have the money? After your buyer has made you an offer, you need to ask for evidence that they have the appropriate finance in place. It is all too common for sales to fall through because the buyer has been unable to secure funding, often after several months have gone by and legal and other costs have been incurred. Consider asking for a non-refundable deposit to demonstrate the buyer's commitment.

\section{Heads of Terms \\ 3 Draw up final Heads of Terms to be signed} by all parties. Whilst this is not a legally binding document (it is usually expressed to be 'Subject to Contract' and subject to completion of due diligence), once signed it does serve to remind the parties exactly what has been agreed and what the terms of the deal are. Once Heads of Terms have been signed, it is difficult for a party to then justify any deviation from this. It is also useful to get the parties thinking about the details of the deal early, so that any difficulties are identified before too many costs have been incurred.

\section{$4 \begin{aligned} & \text { Exclusivity } \\ & \text { The buyer may }\end{aligned}$ \\ The buyer may request an exclusivity period} in order to prevent you from talking to other buyers whilst they find out everything they need to know about your practice. As the seller, you need to keep this period as short as possible and, if the buyer has not yet paid a non-refundable deposit, make sure that you extract one at this point as a condition of granting exclusivity.

\section{Locums}

Following a recent change in legislation, effective since 1 October 2011, agency workers can now be entitled to the same rights as employees. Any buyer will need to be made aware of whether the practice is in the habit of using agency locums and, if so, will need details of the periods they have been working there.

\section{Associate dentists \\ Associate dentists' contracts do not} automatically transfer to the buyer, and so, if the buyer wants to retain them, then new contracts will need to be drawn up.

\section{Transfer of Undertakings \\ (Protection of Employment)} Regulations 2006 ('TUPE')

When a practice is being sold the buyer needs to be aware of the TUPE regulations. This means that current employees' terms of employment will transfer over to the new owner. It is your responsibility to inform your buyer about the agreed individual terms for each member of the team and to inform your employees of the transfer. You must also find out whether the buyer is planning to make any changes that will affect your employees, because you are also under a duty to inform affected employees of any such changes.

\section{Contracts \\ 8 It is important to consider what contracts} the practice has in place, for example, laboratory contracts or contracts for IT maintenance, as these may need to be transferred over to the buyer.

\section{Care Quality Commission ('CQC') \\ The buyer will need to register with the} CQC, which can take more than 120 days. This is best achieved by the seller and buyer entering into a partnership on exchange of contracts (which will probably be necessary in any event if there is an NHS contract involved in the transfer, as explained below), following which the seller will amend their CQC registration to include the buyer. Change in the ownership of practice premises also needs to be registered with the CQC.

\section{0 GDS vs. PDS In order for the buyer to get the} benefit of a GDS contract you must enter into a partnership agreement with the buyer for a period of time after exchange of contracts until the PCT acknowledges the partnership, after which you are able to complete the sale and 'retire' from the practice.

As far as a PDS contract is concerned, there are two options. The simplest is to take advantage of the contractual right to convert to a GDS contract and then follow the process outlined above, but this option is only available for dental services (not orthodontic) contracts. Alternatively, your potential buyer can enter into a new contract with the PCT. In either case the PCT may use this as an opportunity to insist on changes, such as a reduction in the number of UDAs, or otherwise add restrictions to the contract, meaning that the purchase would be less attractive to the buyer. 